\title{
OCENA KNJIGE KORPUSNA TERMINOGRAFIJA: PRIMER ODNOSOV Z JAVNOSTMI
}

\author{
Mojca ŽAGAR KARER \\ Inštitut za slovenski jezik Frana Ramovša, ZRC SAZU
}

Žagar Karer, M. (2014): Ocena knjige Korpusna terminografija: primer odnosov z javnostmi. Slovenščina 2.o, 2 (1): 62-66.

URL: http://www.trojina.org/slovenscina2.o/arhiv/2014/1/Slo2.O_2014_1_o4.pdf.

Monografija Korpusna terminografija: primer odnosov z javnostmi avtorice Nataše Logar je obogatitev slovenske literature s področja korpusnega jezikoslovja, pa tudi s področja terminologije in terminografije sploh. Prinaša natančen in jasen opis uporabe korpusne metodologije za izdelavo terminološke podatkovne zbirke na konkretnem strokovnem področju, in sicer na področju odnosov z javnostmi.

Vsebinsko je knjiga razdeljena na tri dele. Prvi del je posvečen nekorpusnim in delno korpusnim terminološkim slovarjem, v drugem delu je opisan korpus besedil odnosov z javnostmi, v tretjem delu pa terminološka podatkovna zbirka odnosov z javnostmi.

V prvem delu so obravnavani 4 terminološki slovarji (Slovenski elektrotehniški slovar, Vojaški slovar, Planinski terminološki slovar in Islovar), primerjalno pa še Pleteršnikov slovar in SSKJ. Navedeni slovarji so analizirani zlasti s stališča gradivne osnove, kar je pričakovano, saj so razvidnost in dokumentiranost gradiva ter možnost računalniške obdelave besedil glavna dodana vrednost korpusnega pristopa $\mathrm{v}$ terminografiji. Za pregledane slovarje avtorica ugotavlja, da »uresničevanje načel o obsežnem, premišljeno izbranem in po izboru razvidnem ter dokumentiranem gradivu [...] ni bilo vedno dosledno ali pa ga sploh ni bilo« (str. 152). Ob tem je treba dodati, da je tudi v 
predkorpusni dobi nastalo več terminoloških slovarjev, ki so svoje gradivo relativno dobro dokumentirali - času primerno v obliki kartotečnih listkov ali kupov podčrtanih premišljeno izbranih strokovnih besedil. Glede na to, da je v slovenskem prostoru od leta 2000 izšlo skoraj 200 po zasnovi in obsegu zelo raznolikih terminoloških slovarjev, bi bilo analiziranih predkorpusnih terminoloških slovarjev lahko več - pri čemer se seveda zavedamo, da namen te monografije ni bil niti izdelava tipologije terminoloških slovarjev niti natančna analiza gradivne osnove množice nekorpusnih terminoloških slovarjev. Morda pa bi bila smiselna vsaj analiza 3 sodobnejših terminoloških slovarjev, ki so uporabili korpusno gradivo in so $\mathrm{v}$ knjigi le omenjeni (Bibliotekarski terminološki slovar, Turistični terminološki slovar, Terminološki slovar vzgoje in izobraževanja).

Drugi del monografije je dragocen zlasti zaradi natančnega popisa gradnje korpusa besedil odnosov z javnostmi. Korpus je bil zgrajen z namenom izdelave terminološke podatkovne zbirke s področja odnosov z javnostmi. Določena so bila merila za gradnjo korpusa in ob njihovem natačnem opisu (in nazornih primerih) avtorica odkrito spregovori tudi o dilemah pri sprejemanju posameznih odločitev, pri čemer včasih tudi samokritično opozori, da kakšna odločitev morda ni bila optimalna. Tudi zato bo ta del monografije zelo koristen zlasti za tiste bralce, ki se bodo podobnih podvigov lotili sami.

Tretji del je posvečen terminološki podatkovni zbirki. Smiselno se začne pri geslovniku in znotraj tega obravnava liste besed in luščenje terminoloških kandidatov, na koncu pa opiše, kako je potekalo sodelovanje $\mathrm{z}$ dvema področnima strokovnjakoma, ki sta bila ključna pri prehodu s seznama z računalniško izluščenimi terminološkimi kandidati v geslovnik. Opozorjeno je na problem, s katerim se sreča vsak strokovnjak ali skupina strokovnjakov, ki pregleduje sezname izluščenih terminoloških kandidatov - to je vprašanje meje med (terminološko) kolokacijo in terminom. Verjetno je na področju odnosov z javnostmi (ki kot veda po navedbah v knjigi obstaja le nekaj več kot 20 let) teh 
dilem več, kot bi jih bilo na katerem drugem področju, recimo naravoslovnem ali tehničnem - seveda pa je to hipoteza, ki bi jo bilo treba empirično preveriti in presega namen obravnavane monografije. Prav tako iz specifike področja odnosov z javnostmi izvira pogosta zadrega, ali gre za termin s tega strokovnega področja ali s katerega drugega (npr. marketing, organizacijske vede, menedžment, ekonomija, novinarstvo in mediji, statistika, pravo, informacijsko-komunikacijska tehnologija). $\mathrm{S}$ tem problemom se sicer soočamo na vseh strokovnih področjih, ker je značaj znanosti danes bolj interdisciplinaren kot nekoč in so meje med različnimi vedami ponekod precej zabrisane. Ne glede na objektivizacijo, ki jo v terminografski opis prinašajo korpusne metode in predstavlja velik kvalitativni premik $\mathrm{v}$ terminografiji, mimo katerega $v$ prihodnosti ne bo mogel noben resnejši terminografski projekt, je pohvalno tudi avtoričino zavedanje omejitev tega pristopa, saj na str. 112 ugotavlja:

Ob koncu te točke pa je vendarle treba poudariti, da so bili odgovori na vsa tri vprašanja - ali gre za termin ali ne, ali gre za kolokacijo ali ne in ali gre za termin (tudi) tega področja ali ne - kljub objektiviziranemu izhodišču (korpus, luščenje) in kljub temu, da je šlo za skupno odločitev več ljudi, še vedno deloma, morda bi lahko rekli 'strokovno' subjektivni.

Nadaljevanje poglavja se ukvarja s predstavitvijo podatkov v geselskem članku $\mathrm{v}$ različnih terminoloških slovarjih. $\mathrm{V}$ ta namen je bilo pregledanih 10 terminoloških slovarjev, pri čemer avtorica opozarja, da je bil izbor teh slovarjev slučajen in da so zato ugotovitve razumljene le kot kazalniki nekaterih tendenc. Žal so se v izboru znašli nekoliko starejši slovarji (med analiziranimi slovarji ni nobenega, ki bi izšel v zadnjih osmih letih), zato je na podlagi izbranih slovarjev težko sklepati na sodobne tendence glede mikrostrukture geselskega članka.

Novost $\mathrm{v}$ slovenski terminografiji je gotovo poglavje o besedilnem okolju termina, ki je, kot ugotavlja avtorica, v terminoloških slovarjih redkost. Tu gre 
pravzaprav za prenos leksikografske teorije in metodologije na področje terminologije - tudi orodje Besedne skice, s katerim je potekalo luščenje kolokacij, in orodje GDEX, s pomočjo katerega je potekalo avtomatsko pridobivanje zgledov, je bilo primarno razvito za potrebe pedagoškega slovarja angleščine založbe Macmillan, v našem prostoru pa uporabljeno pri pripravi leksikalne baze za slovenščino. Na tem mestu nekoliko pogrešamo vsaj krajšo predstavitev teorije tradicionalne terminologije, ki temelji na pojmovnem pristopu. Če se je terminologija v času, ko se je vzpostavljala kot samostojna veda, poskušala teoretično in metodološko oddaljiti od leksikologije in (poenostavljeno rečeno) razbiranja pomena besed iz sobesedila, se korpusna terminologija temu spet približuje. Če si za trenutek privoščimo izstop iz enega od dveh $\mathrm{v}$ osnovi zelo različnih metodoloških izhodišč in izhajamo iz terminografske prakse, hitro ugotovimo, da termini po svojih značilnostih kljub vsemu bistveno odstopajo od drugih jezikovnih enot (večina jih vzpostavlja hierarhična razmerja z drugimi termini, enopomenskost je veliko pogostejša kot pri splošni leksiki itd.), po drugi strani pa so tudi terminološki sistemi, ki temeljijo na pojmovnih sistemih strok, vedno le približek realnega stanja in še zdaleč niso tako sistematično organizirani, kot bi pričakovali. Zaradi tega bi bil na mestu premislek o možnostih kombiniranja korpusnih metod in pojmovnega pristopa. Seveda pa je predpogoj za začetek širše strokovne razprave dobro poznavanje pojmovnega in korpusnega pristopa ter praktične izkušnje z obojim. Na področju korpusnega pristopa je vrzel uspešno zapolnila prav obravnavana monografija.

V nadaljevanju tretjega poglavja se avtorica posveti možnosti izrabe korpusa pri luščenju definicij in vprašanju normativnosti, ki se mu v terminologiji ni mogoče izogniti. Ugotavlja, da korpusni podatki o pogostnosti, avtorstvu, besedilni vrsti, časovnem razvoju terminov itd. olajšajo in objektivizirajo odločitve v zvezi z normativnostjo. V predkorpusnih časih so se avtorji slovarjev glede rabe različnih izrazov za isti pojem lahko odločali le na osnovi lastnega občutka (in okusa!), danes pa imamo z ustreznimi korpusi na voljo relevantne 
podatke o pogostnosti posameznih terminov, poleg tega pa tudi o njihovi razpršenosti po različnih virih ipd. Oznaki predlagani termin in novi termin sta za potrebe podatkovne zbirke odnosov z javnostmi dobro utemeljeni in smiselni. $\mathrm{V}$ zadnjem delu je predstavljen še primer geselskega članka in mikrostruktura terminološke podatkovne zbirke odnosov z javnostmi, ki smiselno zaokrožuje celotno monografijo (podatkovna zbirka $\mathrm{v}$ času pisanja ocene sicer še ni bila prosto dostopna na portalu Termania). Predstavljene so prednosti spletnega prikaza podatkov, ki med drugim omogoča večnivojskost predstavljenih podatkov, zaradi česar je velika količina podatkov lahko predstavljena bolj pregledno in razumljivo, poleg tega pa omogoča tudi preprosto dopolnjevanje, spreminjanje in izločanje terminov. Konkretnih terminoloških rešitev sicer ni mogoče komentirati na podlagi enega vzorčnega gesla, očitno pa je, da gre v primeru podatkovne zbirke odnosov z javnostmi za precejšen odmik od tipičnih terminoloških slovarjev. Z zanimanjem lahko pričakujemo tudi napovedane raziskave med potencialnimi uporabniki podatkovne zbirke odnosov z javnostmi.

S knjigo Korpusna terminografija smo dobili celovit in izčrpen opis in preizkus korpusne metodologije na konkretnem strokovnem področju, zaradi česar ima delo poleg teoretične tudi uporabno vrednost. Besedilo smiselno dopolnjuje več jasnih in povednih grafičnih ponazoritev, pohvaliti pa je treba tudi avtoričin tekoč in razumljiv slog pisanja ter všečno oblikovanje. Delo je torej obvezno branje za vse, ki jih zanimata korpusna terminografija in terminologija sploh.

To delo je ponujeno pod licenco Creative Commons: Priznanje avtorstvaDeljenje pod enakimi pogoji 2.5 Slovenija.

This work is licensed under the Creative Commons Attribution ShareAlike 2.5 License Slovenia. 